\title{
Familial Hypocholinesterasemia Found in a Family and a New Confirmed Mutation
}

\author{
Weidong Liu, Toshikazu Hada, Kohya Fukui, Hiroyasu Imanishi, \\ Noboru MatsuoKa*, Arata IwasaKi and Kazuya Higashino
}

\begin{abstract}
A 45-year-old man was hospitalized because of acute hepatitis. His serum cholinesterase (ChE) was below $10 \mathrm{IU} / l$ (normal range: 105-240 IU/l) during the disease course and after his recovery. The patient was suspected of having familial hypocholinesterasemia. His family members were healthy except that his father had hypertension and gall stones. Analysis of ChE gene in the propositus and his family revealed three point mutations at nucleotides 298 (CCA to TCA), 1,410 (CGT to CGG) and 1,615 (GCA to ACA). The first mutation caused an amino acid change at codon 100 from proline to serine, which was a new mutation not previously reported, but the second one was a silent mutation. The third mutation resulted in an amino acid alteration from alanine to threonine at codon 539 in exon 4 of the ChE gene. The mode of transmission of these mutations is described.
\end{abstract}

(Internal Medicine 36: 9-13, 1997)

Key words: cholinesterase, gene analysis, point mutation

\section{Introduction}

Patients with a- or hypocholinesterasemia generally have no signs or symptoms and can have a healthy daily life. However, when these patients must be injected with a muscle relaxant, succinylcholine, which is broken down by serum cholinesterase (ChE; EC 3.1.1.8, also called butyrylcholinesterase), they may develop prolonged apnea because of the lack of this enzyme. Thus, it is important to evaluate the levels of serum $\mathrm{ChE}$ in all patients. DNA sequencing of serum $\mathrm{ChE}$ has already been accomplished $(1,2)$ and several genetic variants causing a- or hypocholinesterasemia have been reported (3-7). In the present study, we carried out gene analysis of familial hypocholinesterasemia in a family of five.

For editorial comment, see $\mathrm{p} 1$.

\section{Materials and Methods}

\section{Patients}

The propositus, a 45-year-old man, was hospitalized with Atype acute viral hepatitis. On admission, serum aspartate aminotransferase (GOT) and alanine aminotransferase (GPT) were
2,601 and 3,321 IU/l, respectively. The titer of IgM antibody to hepatitis A virus was 4.4 (normal range: <1.0 C.I.). Total bilirubin was $4.6 \mathrm{mg} / \mathrm{dl}$. His serum ChE fell below $10 \mathrm{IU} / \mathrm{l}$ (normal range: 105-240) during the disease course and persisted at that level after recovery. He was suspected of having familial hypocholinesterasemia, and his family members were examined for their serum $\mathrm{ChE}$ levels. The family tree is illustrated in Fig. 1. All family members were healthy except his father had hypertension and gall stones which were well controlled by his doctor. None of the family members were receiving any medications affecting serum ChE activity.

The propositus and his elder brother had serum ChE levels below $10 \mathrm{IU} / l$, and were suspected to be homozygous for the silent ChE gene. Serum ChE levels of the patient's father, mother and younger brother were around or below the normal lower limits and they were suspected to be heterozygous for the same gene.

\section{Enzyme assay}

Serum ChE activity was determined using a Choline C "Kokusai" kit (Kokusai Shiyaku, Tokyo) in which the substrate was dimethoxybenzoylthiocholine. Dibucaine and fluoride numbers were determined using benzoylcholine as a substrate as described previously (6).

From the Third Department of Internal Medicine, Hyogo College of Medicine, Nishinomiya and *Matsuoka Clinic, Yatsushiro 


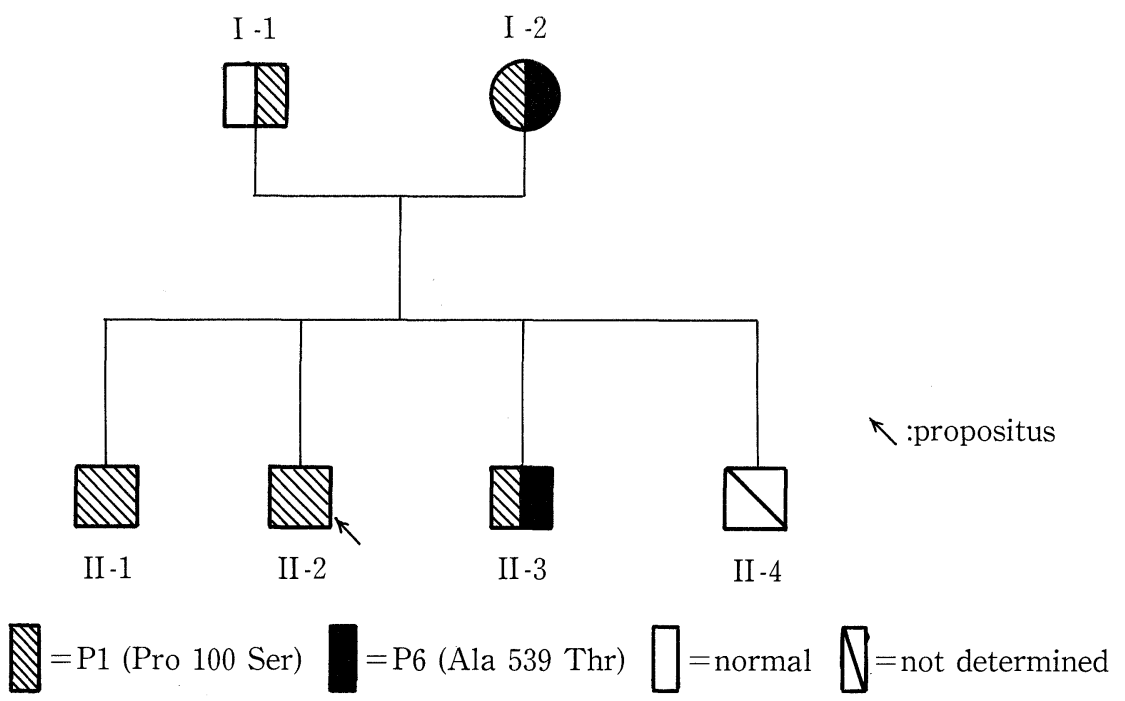

Figure 1. Family tree of the patients with hypocholinesterasemia. Boxes indicate males and circle indicates female.

\section{Blood collection and plasma phenotyping}

Whole blood samples were collected from 5 members of the family. Plasma phenotypes were determined from $\mathrm{ChE}$ activity using benzoylcholine as a substrate, with inhibition by dibucaine and sodium fluoride. The dibucaine and fluoride numbers were determined using $10 \mu \mathrm{M}$ dibucaine and $50 \mu \mathrm{M} \mathrm{NaF}$, respectively, according to methods previously reported $(8,9)$.

\section{DNA amplification and sequencing}

White-blood cell DNA from 5 persons of the family was extracted using a DNA extraction kit (Microprobe Corporation, CA, USA). Exons, 23 and 4, which encode the entire mature protein of $\mathrm{ChE}$, were individually amplified by a polymerase chain reaction (PCR) method using a HPLC-purified primer set and Taq DNA polymerase (Takara Shuzo Corporation, Shiga). The primers for exon 2 were the same as those described by Maekawa et al (7). The primers for exons 3 and 4 were newly designed for this study (Table 1). A total of 35 rounds of amplification were performed, each round consisting of a denaturation step at $94^{\circ} \mathrm{C}$ for 1 minute, an annealing step at $55^{\circ} \mathrm{C}$ for 1 minute and extension step at $72^{\circ} \mathrm{C}$ for 1.5 minutes. After confirming the sizes and homogeneity of the PCR products, direct sequencing of the entire coding region of the $\mathrm{ChE}$ gene was performed using a dye terminator cycle sequencing core kit (Perkin-Elmer Corporation, CA, USA) and an ABI 373A DNA sequencer (Perkin-Elmer Corporation).

\section{Results}

\section{Plasma ChE activity and phenotyping}

As shown in Table 2, the propositus (II-2) and his elder brother (II-1) had very low serum ChE activity. The propositus' father (I-1) had serum enzyme activity around the normal lower limit. The propositus' mother and his younger brother (I-2, II3) had serum enzyme activity below the normal lower limits. The dibucaine and fluoride numbers examined for two of the persons (I-1, I-2) were within the normal range.

\section{DNA analysis within the pedigree}

As shown in Fig. 1 and Table 2, the propositus and his elder brother both had a homozygous missense mutation at nucleotide 298 (CCA to TCA) which caused the replacement of proline by serine at codon 100 (Pro 100 Ser) in exon 2 of the $\mathrm{ChE}$ gene. Figure $2 \mathrm{~A}$ shows the results of direct sequencing of the amplified products of the propositus, demonstrating a $\mathrm{C}$ to $\mathrm{T}$ transversion at nucleotide 298. This mutation has not previ-

Table 1. Primer Sequences Used for Amplification of Cholinesterase Gene Newly Designed for This Study

\begin{tabular}{lccc}
\hline Primer & Nucleotide location & Sequence (5' to 3') & Amplified region \\
\hline AP 11' & Intron 2 & AGCTCTGTGAACAGTGTTAGAA & exon 3 \\
AP 12' & Intron 3 & CACCGTGCCTTGGAGAGTATAC & \\
& & & \\
AP 5' & Intron 3 & CTGTGTAGTTAGAGAAAATGGC & exon 4 \\
AP 6' & Intron 4 & CCTTCTGGCATTTTTGTTTCAGC & \\
\hline
\end{tabular}


Table 2. ChE Activity and the Location of Point Mutations in Each Individual Family Member

\begin{tabular}{lclllll}
\hline & I-1 & I-2 & II-1 & II-2 & II-3 & II-4 \\
\hline Age (year) & 73 & 70 & 48 & 47 & 45 & 42 \\
ChE (105-240 IU/l) & 109 & 77 & 10 & 10 & 86 & nd \\
P1 (exon 2) & hetero & hetero & homo & homo & hetero & \\
P6 (exon 4) & normal & hetero & normal normal hetero & \\
\hline
\end{tabular}

nd: not determined, hetero: heterozygous, homo: homozygous, P1: point mutation at nucleotide position 298 (CCA to TCA), which causes an amino acid alteration at codon 100 from proline to serine, P6: point mutation at nucleotide position 1615 (GCA to ACA), which causes an amino acid alteration at codon 539 from alanine to threonine.

ously been reported. In addition, another homozygous nonsense mutation was observed at nucleotide 1,410 (CGT to $\mathrm{CGG}$ ) for both the propositus and his elder brother (Fig. 2B). In this case, no amino acid substitution occurred. We performed further DNA analyses of the ChE gene for the remaining three family members (I-1, I-2 and II-3). The propositus' father (I-1), mother (I-2) and younger brother (II-3) also had a heterozygous missense mutation at nucleotide 298 (CCA to TCA) which resulted in an amino acid change from proline to serine at codon 100 in exon 2 of the $\mathrm{ChE}$ gene. Another heterozygous missense mutation was found in the propositus' mother and younger brother at nucleotide 1,615 (GCA to ACA) which caused an amino acid change from alanine to threonine at codon 539 in exon 4 of the $\mathrm{ChE}$ gene. These results indicated that the propositus' mother and younger brother were compound heterozygotes: CCA (Pro) to TCA (Ser) at codon 100 and GCA (Ala) to ACA (Thr) at codon 539 (Figs. 1, 2C, 2D and Table 2). A homozygous nonsense mutation observed at nucleotide 1,410 (CGT to CGG) for the propositus and his elder brother was also found in the other family members. Since a homozygous nonsense mutation was observed in all of the family members, we examined whether this mutation occurred in normal individuals. Twenty normal individuals with normal ChE activity all had a homozygous nonsense mutation at nucleotide 1,410 (CGT to CGG).

\section{Discussion}

Serum ChE is generally considered to be synthesized in the liver and released into the blood stream. Serum $\mathrm{ChE}$ is routinely measured as a test of liver function. Low serum $\mathrm{ChE}$ activity has been reported in acute and chronic liver diseases (10), and has also been noted in several genetic hypocholinesterasemia (37). Therefore, discrimination of liver diseases and genetic hypocholinesterasemia is very important. The present propositus was suspected of having genetic hypocholinesterasemia because of low serum ChE activity after recovery from acute hepatitis. Thus, the possibility of genetic hypocholinesterasemia should be considered in patients with liver disease.

The phenotyping method introduced by Kalow and Genest
(8), based on the dibucaine number, is a useful and reliable method for determining whether a person has atypical ChE. Atypical ChE has a special feature in that the atypical allele can be detected in homozygotes as well as heterozygotes (3). It has been reported that most of the other variants can not be identified when they occur in combination with the usual allele (3). It is therefore difficult to discriminate by phenotyping tests whether a person is a carrier of the silent, fluoride, $\mathrm{H}, \mathrm{J}, \mathrm{K}$, or some other variants (3). Our propositus' father (I-1) and mother (I-2) had normal dibucaine and fluoride numbers. Therefore, neither the point mutation at codon 100 nor the point mutation at codon 539 of the amino acid sequence seemed to affect the dibucaine number. However, it is not clear at present whether either or both mutations affect the fluoride number. In the present study, we identified three point mutations, two of which were located in exon 2 and the other one was in exon 4 of the ChE gene. The first point mutation at codon 100 of the amino acid sequence is newly identified and appears to cause low ChE activity (Fig. 1 and Table 2). We already found this mutation in another family with genetic hypocholinesterasemia in addition to the present family, as well as two sporadic cases (unpublished data). However, the mechanism which causes hypocholinesterasemia remains to be elucidated. The second mutation at codon 470 of the amino acid sequence is a silent mutation and does not result in amino acid alteration. As this mutation could be detected in all family members as homozygotes, we suspected that this mutation occurs in normal persons, and this was confirmed in 20 persons with normal $\mathrm{ChE}$ activity. Considering our data in comparison with the original report concerning the DNA sequence of the ChE gene, this mutation may occur only in Japanese. Ethnic distribution of this mutation should be clarified in the future. The third mutation at codon 539 of the amino acid sequence was previously reported by Bartels et al (11) and is called the $\mathrm{K}$ variant. Rubinstein et al (12) found that the $\mathrm{K}$ variant is associated with a $33 \%$ reduction in serum $\mathrm{ChE}$ activity. Considering the enzyme activities of our subjects (I-2, II-3), our findings are consistent with those of Rubinstein et al. We found this mutation in another family in addition to the present family and in one sporadic case (unpublished data).

As reported by Neville et al (13), if plural point mutations occur simultaneously in one ChE molecule, these point mutations may interact with each other intramolecularly. Then, in one case, one point mutation magnifies the effect of another point mutation. In another case, the reverse phenomenon can be observed. Although at least 10 different allelic forms have been described (13), each phenotype, which is expressed with a characteristic peptide sequence, can be modified by interaction with another mutation and cannot be identified by conventional tests such as ChE activity, inhibition rate by several inhibitors and so on. In the present family, homozygous mutation at nucleotide 298 in patients II- 1 and II- 2 caused an anomalously low serum ChE activity and a heterozygous mutation in patient I- 1 caused a moderate reduction of the enzyme activity. The reduction of $\mathrm{ChE}$ activity observed in patients I-2 and II-3 seemed to occur in an additive fashion of each effect of two heterozygous mutations. Further investigation is needed to 

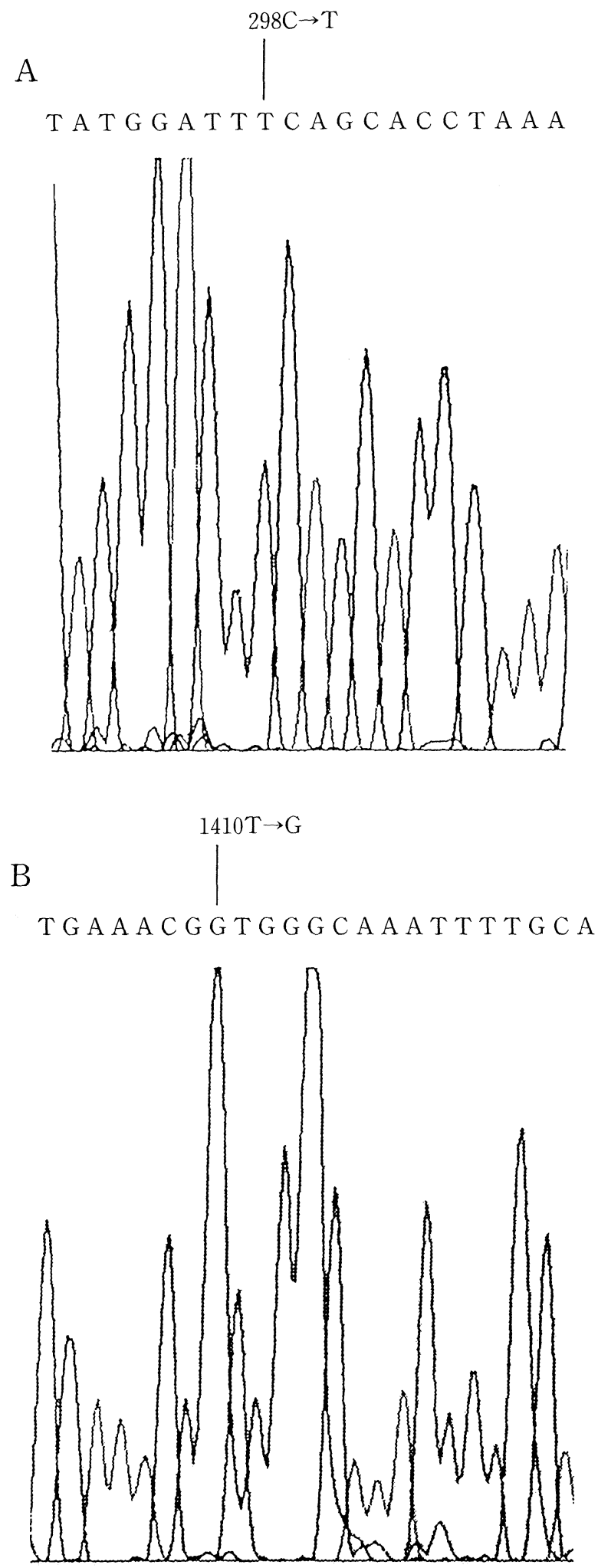

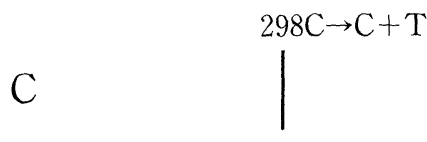

T G G A T T C C A G C A C C T A A A C C
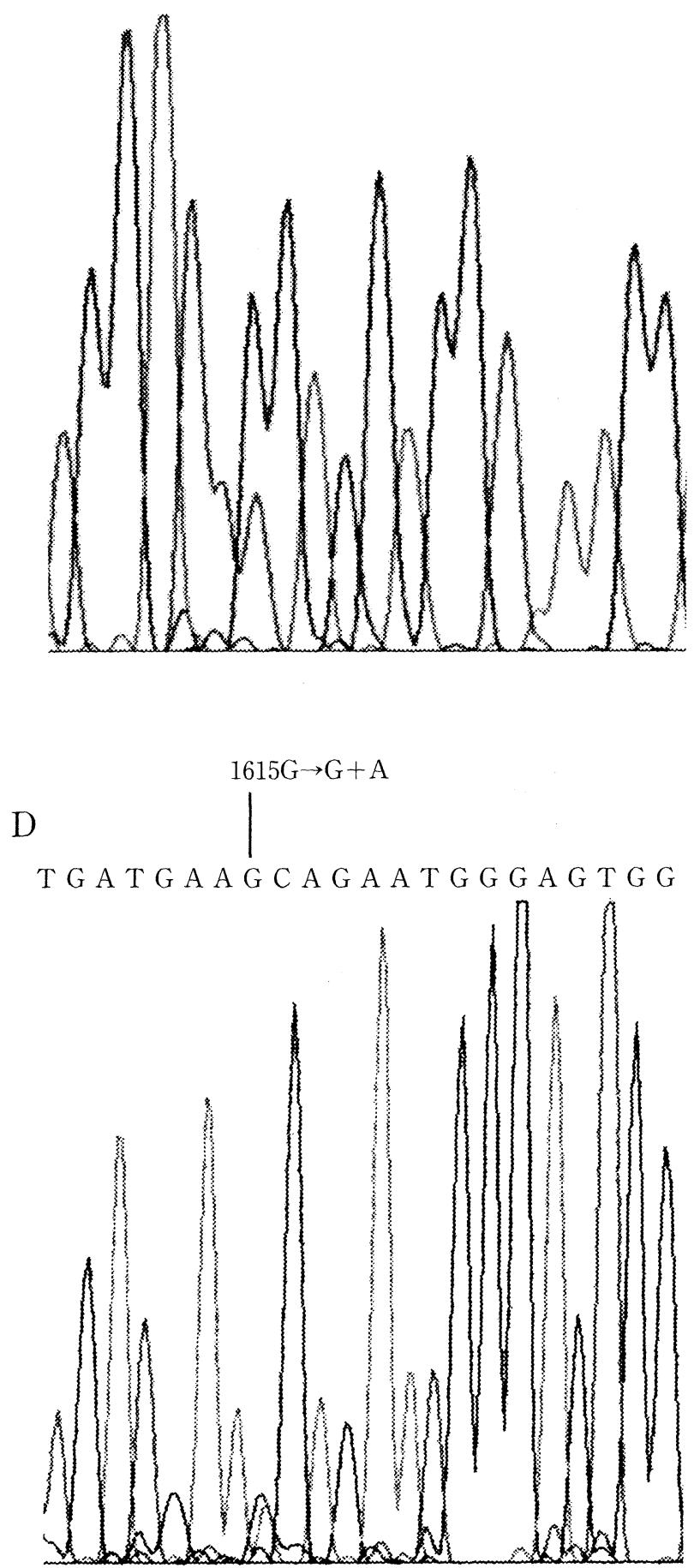

Figure 2. A) DNA sequencing from the propositus (II-2) representing a homozygous missense mutation at nucleotide 298 (C to T). B) DNA sequencing of the propositus' father (I-1) representing a homozygous point mutation at nucleotide 1,410 (T to G). C) and D) DNA sequencing from the propositus's mother demonstrating a heterozygous missense mutation at nucleotides 298 $(C$ to $\mathrm{C}+\mathrm{T})$ and 1,615 ( $\mathrm{G}$ to $\mathrm{G}+\mathrm{A})$, respectively. 


\section{Hypocholinesterasemia in a Family}

clarify the intramolecular relationships between ChE activity and point mutations.

Sequencing the DNA of family members demonstrated that the propositus' father carried two point mutations at codons 100 and 470 on one DNA strand and one mutation at codon 470 on the other DNA strand. The propositus' mother carried two point mutations at codons 100 and 470 on one DNA strand and two point mutations at codons 470 and 539 on the other DNA strand. In summary, we described familial hypocholinesterasemia, and confirmed a new mutation which causes reduced serum $\mathrm{ChE}$ activity. However, the mechanism which resulted in hypocholinesterasemia remains to be elucidated. In addition, another nonsense mutation was observed in all members examined in the present study. Further investigation is needed to clarify the ethnic distribution of this mutation.

\section{References}

1) Prody CA, Zevin-Sonkin D, Gnatt A, Goldberg O, Soreq H. Isolation and characterization of full length cDNA clones coding for cholinesterase from fetal human tissues. Proc Natl Acad Sci USA 84: 3555, 1987.

2) McTiernan $C$, Adkins $S$, Chatonnet A, et al. Brain cDNA clone for human cholinesterase. Proc Natl Acad Sci USA 84: 6682, 1987.

3) La Du BN, Bartels CF, Nogueira CP, Arpagaus M, Lockridge O. Proposed nomenclature for human butyrylcholinesterase genetic variants identified by DNA sequencing. Cell Mol Neurobiol 11: 79, 1991.
4) Muratani K, Hada T, Yamamoto $Y$, et al. Inactivation of the cholinesterase gene by Alu insertion: possible mechanism for human gene transposition. Proc Natl Acad Sci USA 88: 11315, 1991.

5) Bartels CF, James K, La Du BN. DNA mutations associated with the human butyrylcholinesterase J-variant. Am J Hum Genet 50: 1104, 1992.

6) Hada T, Muratani K, Ohue T, et al. A variant serum cholinesterase and a confirmed point mutation at Gly-365 to Arg found in a patient with liver cirrhosis. Intern Med 31: 357, 1992.

7) Maekawa M, Sudo K, Kanno T, et al. Genetic basis of the silent phenotype of serum butyrylcholinesterase in three compound heterozygotes. Clin Chim Acta 235: 41, 1995.

8) Kalow W, Genest K. A method for the detection of atypical forms of human cholinesterase. Determination of dibucaine numbers. Can J Biochem Physiol 35: 339, 1957.

9) Harris H, Whittaker M. Differential inhibition of human serum cholinesterase with fluoride: Recognition of two new phenotypes. Nature (Lond.) 191: 496, 1961.

10) Brown SS, Kalow W, Pilz W, Whittaker M, Woronick CL. The plasma cholinesterase: a new perspective. Adv Clin Chem 22: 1, 1981.

11) Bartels CF, yan der Spek A, Lochridge $O, L a D u B N$. A polymorphism (K variant?) of human serum cholinesterase at nucleotide 1615 , coding for Ala/Thr 539. FASEB J 3: A741, 1989.

12) Rubinstein HM, Dietz AA, Lubrano T. $E_{1}^{k}$, another quantitative variant at cholinesterase locus 1. J Med Genet 15: 27, 1978.

13) Neville LF, Gnatt A, Loewenstein Y, Seidman S, Ehrlich G, Soreq H. Intramolecular relationships in cholinesterases revealed by oocyte expression of site-directed and natural variants of human BCHE. EMBO J 11: $1641,1992$. 